\title{
Corrosion inhibition of a composite inhibitor containing imidazoline on carbon steel in simulated reverse osmosis product water of seawater
}

\author{
S.H. Liu, ${ }^{1 *}$ Y.N. Wang, ${ }^{1}$ B.X. Yuan, ${ }^{1}$ W.T. Dong ${ }^{2}$ and Q.Q. Liao ${ }^{1}$ \\ ${ }^{1}$ Shanghai University of Electric Power, Shanghai Key Laboratory of Materials Protection \\ and Advanced Materials in Electric Power, Shanghai 20009, China \\ ${ }^{2}$ Shanghai Fakai Chemical Industry Co. Ltd., Shanghai 201505, China \\ E-mail:15075088709@,163.com
}

\begin{abstract}
The synergistic performance of corrosion inhibition of 2-undecyl- $N$-carboxymethyl- $N$ hydroxyethyl imidazoline (UHCI) and $\mathrm{ZnSO}_{4}$ on $20 \#$ carbon steel surface in simulated reverse osmosis product water of seawater was investigated by electrochemical methods, scanning atomic force microscopy (AFM) and X-ray diffraction (XRD). The results show that the composite inhibitor acts as a mixed type inhibitor, reducing the corrosion of carbon steel effectively and the inhibition efficiency reaches the best values when the mass concentration ratio of $\mathrm{UHCI}$ and $\mathrm{ZnSO}_{4}$ is $50: 50$ at the total concentration of the solution is $100 \mathrm{mg} \cdot \mathrm{L}^{-1}$ where the corrosion inhibition efficiency reaches $96.99 \%$. The UHCI molecules adsorbed on metal surfaces, controlling the anodic reaction. $\mathrm{ZnSO}_{4}$ is deposited on the metal surface in the form of $\mathrm{Zn}(\mathrm{OH})_{2}$, controlling the cathodic reaction.
\end{abstract}

Keywords: carbon steel, composite inhibitor, simulated $R O$ product water, polarization, EIS, AFM, XRD.

Received: March 13, 2016. Revised: September 23, 2016. Published: September 26, 2016.

doi: $10.17675 / 2305-6894-2016-5-4-3$

\section{Introduction}

At present, with the increasing shortage of fresh water resource, the study on seawater desalination is attracting more and more attention. Reverse osmosis (RO) has increasingly become one of the main methods of seawater desalination[1,2]; it has broad application prospects in the high water consuming industries, such as coastal iron and steel enterprises, coastal power plant, chemical factories, and in other fields [3]. However, due to carbon dioxide content, the $\mathrm{RO}$ product water presents a weak acid and the $\mathrm{pH}$ value is about 6.5, so it still has corrosivity on the water distribution network which uses carbon steel as its main material, threatening the safe operation of the water distribution network [4-7]. Some documents $[8,9]$ have reported that the corrosion rust layer of carbon steel in RO product water consists of inner layer $\mathrm{Fe}_{3} \mathrm{O}_{4}$ and outer layer $\gamma$-FeOOH. The studies of Yin [10] and $\mathrm{Hu}$ [11] show the primary reason for the high-speed corrosion of carbon steel in the RO product water is that the weak acid of the solution causes the $\gamma-\mathrm{FeOOH}$ 
transforming into conductive $\mathrm{Fe}_{3} \mathrm{O}_{4}$ to be accelerated, and the rust layer is discontinuous, thus it cannot hinder the diffusion of oxygen. In order to improve the lifespan of the water distribution network, usually adding corrosion inhibitor in the RO product water $[12,13]$, exchanging the materials or adjusting the hardness and alkalinity of the RO product water to reduce the corrosion of the metal materials of the water distribution network.

The inhibitor, 2-undecyl- $N$-carboxymethyl- $N$-hydroxyethyl imidazoline (UHCI), used in this study is a kind of environmentally friendly inhibitor, which has been widely used in pickling and the liquid pipeline transportation [14-16]. However, there are few researches about the corrosion inhibition of imidazoline corrosion inhibitor and its composite corrosion inhibitor on carbon steel in $\mathrm{RO}$ product water. Therefore, in this paper, the performance of the corrosion inhibition of UHCI and $\mathrm{ZnSO}_{4}$ on $20 \#$ carbon steel surface in simulated RO product water has been studied with electrochemical methods, and the inhibition mechanism is also discussed by surface analysis technique.

\section{Experimental methods}

\subsection{Materials and chemicals}

Experimental materials used in this work were 20\# carbon steel, and the composition of the metal in wt. $\%$ is C $0.17-0.23$, Si 0.17-0.37, Mn 0.35-0.65, $\mathrm{P} \leq 0.035, \mathrm{~S} \leq 0.035, \mathrm{Cr} \leq 0.25$, $\mathrm{Ni} \leq 0.30, \mathrm{Cu} \leq 0.25$, bal. Fe. The size of the electrochemical samples was $10 \times 10 \times 2 \mathrm{~mm}^{3}$, and the samples were welded with copper wires and sealed with an epoxy resin except the working face. The specimens were orderly polished with metallographic silicon carbide abrasive paper from 1\# up to 6\#. The oil contamination on the surface of the specimens was cleaned with ethanol, distilled water. The surface was then dried before the tests.

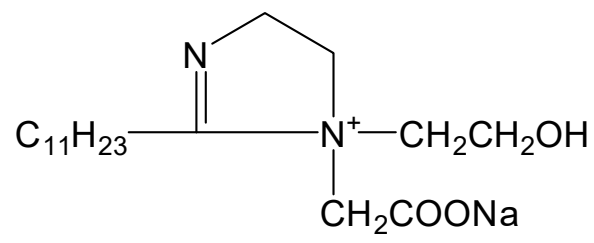

Figure 1. Structure of imidazoline.

The inhibitor, UHCI, used in the experiments, is a sodium salt, which was produced by Shanghai Fakai Chemical Industry Co. Ltd., Shanghai, China. The structure of UHCI is shown in Figure 1. The test solution, which simulated RO product water of seawater, is shown in Table 1.

Table 1. Composition of simulated RO product water.

\begin{tabular}{cccccccccc}
\hline $\begin{array}{c}\mathbf{N a}^{+}, \\
\mathbf{m g} \cdot \mathbf{L}^{-1}\end{array}$ & $\begin{array}{c}\mathbf{C a}^{2+}, \\
\mathbf{m g} \cdot \mathbf{L}^{-1}\end{array}$ & $\begin{array}{c}\mathbf{M g}^{2+}, \\
\mathbf{m g} \cdot \mathbf{L}^{-1}\end{array}$ & $\begin{array}{c}\mathbf{F e}^{3+}, \\
\mathbf{m g} \cdot \mathbf{L}^{-1}\end{array}$ & $\begin{array}{c}\mathbf{C l}^{-}, \\
\mathbf{m g} \cdot \mathbf{L}^{-1}\end{array}$ & $\begin{array}{c}\mathbf{S O}_{4}^{2-}, \\
\mathbf{m g} \cdot \mathbf{L}^{-1}\end{array}$ & $\begin{array}{c}\mathbf{H C O} \\
\mathbf{m g} \cdot \mathbf{L}^{-1}\end{array}$ & $\begin{array}{c}\mathbf{C O}_{2,}, \\
\mathbf{m g} \cdot \mathbf{L}^{-1}\end{array}$ & $\begin{array}{c}\text { Conductivity, } \\
\boldsymbol{\mu S} \cdot \mathbf{c m}^{-1}\end{array}$ & $\mathbf{p H}$ \\
\hline 52.47 & 0.3000 & 0.06000 & 0.09100 & 79.00 & 1.578 & 3.722 & 2.376 & 238.0 & 6.54 \\
\hline
\end{tabular}




\subsection{Electrochemical measurements}

An EG\&G Princeton Applied Research model 2273 Potentiostat/Galvanostat was used to perform the electrochemical experiments, which were done in a conventional threeelectrode cell with a saturated calomel electrode (SCE) as the reference electrode (RE), a platinum counter electrode (CE), and 20\# carbon steel as the working electrode (WE). The flow conditions in the experimental process were simulated by rotation coupon instrument, with rotating speed of $95 \mathrm{rpm}$ (linear speed $0.4 \mathrm{~m} / \mathrm{s}$ ) [17]. EIS measurements were carried out using a sinusoidal potential perturbation of $5 \mathrm{mV}$ in a frequency range from $0.05 \mathrm{~Hz}$ to $100 \mathrm{kHz}$. Polarization curve was recorded in the potentials region $\pm 250 \mathrm{mV}$ (vs. OCP) with a sweep rate of $1 \mathrm{mV} \cdot \mathrm{s}^{-1}$. All the potential values were referred to SCE and the temperature during the measurements was ambient temperature.

\subsection{Surface analysis}

AFM analysis of the surface was performed with Agilent 5500AFM/SPM. The chemical composition of the surface of the specimens in test solutions was investigated by XRD. BRURER D8 ADVANCE X-ray diffraction instrument was used to determine the composition of the surface film and the result was analysed by Jade 6.0 software.

\section{Results and discussion}

\subsection{Polarization curve measurement}

Figure 2 shows the polarization curves of carbon steel electrodes in simulated RO product water with different concentration ratios of UHCI and $\mathrm{ZnSO}_{4}$ after one day of immersion. The result, corrosion potential $\left(E_{\text {corr }}\right)$, corrosion current density $\left(i_{\text {corr }}\right)$ and inhibition efficiency $\left(\eta_{1}\right)$, fitted by the PowerSuite software, is listed in Table 2. The inhibition efficiency $\left(\eta_{1}\right)$ is obtained from the corrosion current density according to:

$$
\eta_{1}=\frac{i_{\text {corr }}^{0}-i_{\text {corr }}}{i_{\text {corr }}^{0}} \times 100 \%,
$$

where $i_{\text {corr }}^{0}$ is the corrosion current density of specimens after immersion in simulated RO product water for one day without inhibitor, $i_{\text {corr }}$ is the corrosion current density of specimens after immersion in simulated $\mathrm{RO}$ product water for one day with different concentration ratios of $\mathrm{UHCI}$ and $\mathrm{ZnSO}_{4}$.

Compared with the blank sample, both the cathodic polarization curves and the anodic polarization curves are changed after adding the inhibitor, as shown in Figure 2.The current density of cathode and anode are decreased, it indicates that the inhibitor belongs to mixed corrosion inhibitor[18], which can inhibit the cathodic reaction as well as the anodic reaction. According to the Table 2, with the increase of UHCI proportion, the corrosion potential moves to a positive direction, the corrosion current density, however, firstly decreases and reaches the minimum when the mass concentration ratio of UHCI and 
$\mathrm{ZnSO}_{4}$ is 50:50; then increases with the concentration of UHCI continue increases to $100 \mathrm{mg} \cdot \mathrm{L}^{-1}$. It suggests that the inhibitor has the best inhibition effect when the ratio of $\mathrm{UHCI}$ and $\mathrm{ZnSO}_{4}$ is 50:50. In the case of equal total concentration, the corrosion current density of the composite inhibitor is smaller than that of single UHCI or $\mathrm{ZnSO}_{4}$, it can be explained by the synergistic effect of UHCI and $\mathrm{ZnSO}_{4}$.

Table 2. The fitting results of polarization curves.

\begin{tabular}{cccc}
\hline $\mathbf{U H C I}: \mathbf{Z n S O}_{\mathbf{4}}, \mathbf{m g} \cdot \mathbf{L}^{-\mathbf{1}}$ & $\boldsymbol{E}_{\text {corr }}, \mathbf{m V}(\boldsymbol{v s .} \mathbf{S C E})$ & $\boldsymbol{i}_{\text {corr }}, \boldsymbol{\mu} \mathbf{A} \cdot \mathbf{c m}^{-\mathbf{2}}$ & $\boldsymbol{\eta}, \boldsymbol{\%}$ \\
\hline 0 & -654.8 & 64.79 & 0 \\
$100 \mathrm{UHCI}$ & -399.9 & 20.80 & 67.89 \\
$100 \mathrm{ZnSO}_{4}$ & -661.9 & 58.75 & 9.320 \\
$20: 80$ & -647.4 & 49.98 & 22.86 \\
$40: 60$ & -624.7 & 8.360 & 87.09 \\
$50: 50$ & -580.1 & 1.945 & 96.99 \\
$60: 40$ & -569.2 & 3.951 & 93.90 \\
$80: 20$ & -515.9 & 4.889 & 92.45 \\
\hline
\end{tabular}

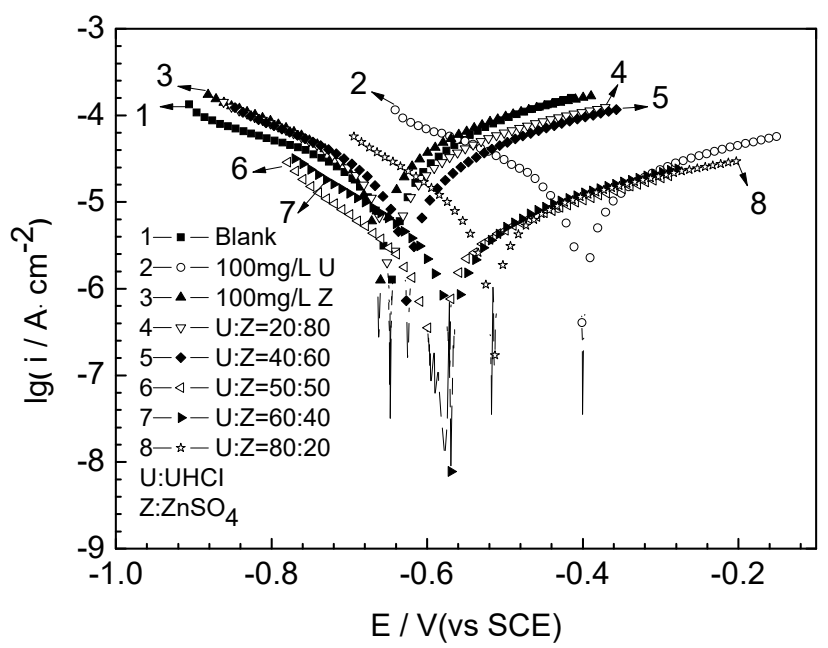

Figure 2. Polarization curves of carbon steel electrodes in simulated RO product water with different ratios of $\mathrm{UHCI}$ and $\mathrm{ZnSO}_{4}$.

\subsection{EIS studies}

The Nyquist plots and Bode plots of carbon steel electrodes in simulated RO product water for one day with different mass concentration ratios of UHCI and $\mathrm{ZnSO}_{4}$ are shown in Figure 3. Table 3 gives the fitting results of the Zsimpwin software. The inhibition efficiency $\left(\eta_{2}\right)$ is calculated using charge transfer resistance $\left(R_{\mathrm{ct}}\right)$ as follows: 


$$
\eta_{2}=\frac{R_{\mathrm{ct}}-R_{\mathrm{ct}}^{0}}{R_{\mathrm{ct}}} \times 100 \%,
$$

where $R_{\mathrm{ct}}$ and $R_{\mathrm{ct}}^{0}$ are the charge transfer resistance in different mass concentration ratios of $\mathrm{UHCI}$ and $\mathrm{ZnSO}_{4}$ and blank solution after one day immersion, respectively.
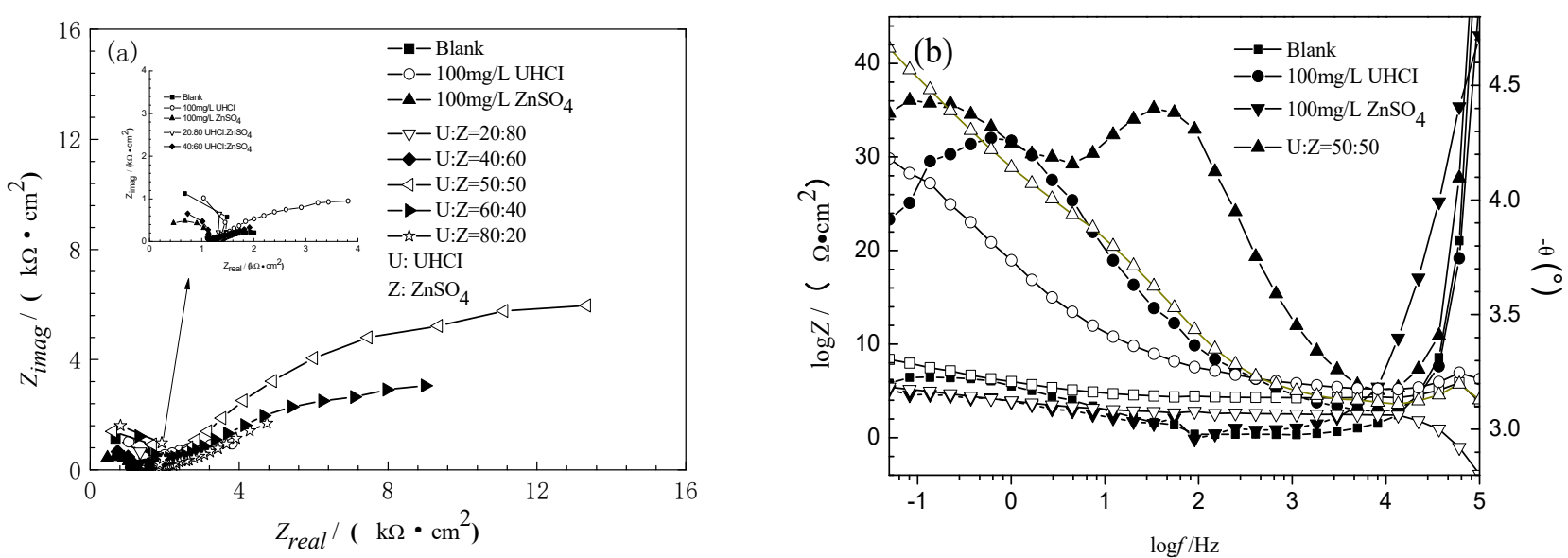

Figure 3. The Nyquist plots and Bode plots of carbon steel electrodes in simulated RO product water with different ratios of UHCI and $\mathrm{ZnSO}_{4}$

Table 3. Electrochemical parameters of the equivalent circuits obtained by fitting the experimental results of EIS.

\begin{tabular}{ccccccc}
\hline $\begin{array}{c}\text { Concentration, } \\
\mathbf{m g} \cdot \mathbf{L}^{-1}\end{array}$ & $\begin{array}{c}\boldsymbol{R}_{\mathbf{s}}, \\
\mathbf{k} \boldsymbol{\Omega} \cdot \mathbf{c m}^{2}\end{array}$ & $\begin{array}{c}\boldsymbol{R}_{\mathbf{f}}, \\
\mathbf{k} \boldsymbol{\Omega} \cdot \mathbf{c m}^{2}\end{array}$ & $\begin{array}{c}\boldsymbol{C P} \boldsymbol{E}_{\mathbf{f}}, \\
\boldsymbol{\mu} \boldsymbol{\Omega}^{-1} \cdot \mathbf{c m}^{-2} \cdot \mathbf{s}^{\mathbf{n}}\end{array}$ & $\begin{array}{c}\boldsymbol{R}_{\mathrm{ct}}, \\
\mathbf{k} \boldsymbol{\Omega} \cdot \mathbf{c m}^{2}\end{array}$ & $\begin{array}{c}\boldsymbol{C P} \boldsymbol{E}_{\mathrm{dl}}, \\
\boldsymbol{\mu} \boldsymbol{\Omega}^{-1} \cdot \mathbf{c m}^{-2} \cdot \mathbf{s}^{\mathbf{n}}\end{array}$ & $\begin{array}{c}\boldsymbol{\eta}_{\mathbf{2}}, \\
\mathbf{\%}\end{array}$ \\
\hline 0 & 1.365 & - & - & 1.011 & 1116 & - \\
$100 \mathrm{UHCI}$ & 1.265 & - & - & 4.102 & 1067 & 75.35 \\
$100 \mathrm{ZnSO}_{4}$ & 1.447 & - & - & 1.121 & 2039 & 9.810 \\
$20: 80$ & 1.526 & 1.210 & 536.2 & 1.480 & 79.83 & 31.69 \\
$40: 60$ & 1.484 & 1.094 & 385.4 & 3.804 & 69.24 & 73.42 \\
$50: 50$ & 1.225 & 1.640 & 21.55 & 27.21 & 62.36 & 96.28 \\
$60: 40$ & 1.539 & 1.097 & 11.07 & 12.30 & 127.2 & 91.78 \\
$80: 20$ & 1.168 & 5.705 & 7.317 & 10.03 & 47.27 & 89.92 \\
\hline
\end{tabular}

As shown in Figure 3(a), with an increase in the ratio of UHCI and $\mathrm{ZnSO}_{4}$, the capacitive impedance loops initially increase and then reduce when the concentration of the solution is $100 \mathrm{mg} \mathrm{L}^{-1}$, which indicates that the composite inhibitor has good corrosion inhibition for carbon steel in simulated RO product water. Among all the impedance loops, 
it is the biggest when the mass concentration ratio of UHCI and $\mathrm{ZnSO}_{4}$ is $50: 50$, indicating that the inhibition effect reaches the best as the ratio is $50: 50$. Figure $3(b)$ shows that there is only one time constant in the Bode diagram of blank solution and the single presence of UHCI and $\mathrm{ZnSO}_{4}$, while there are two time constants after adding the composite inhibitor. Therefore, it can be explained by the equivalent circuit models of EIS in Figure $4(a)$ and $(b) . R_{\mathrm{S}}$ represents the solution resistance, constant phase angle element $\mathrm{CPE}$ is used to replace capacitance because of the exist of dispersion effect, the parameter $\mathrm{CPE}_{\mathrm{f}}$ represents the capacitive behavior of the film formed by the action between the corrosion inhibitors and metal surface, coupled with a film resistance $R_{\mathrm{f}} . C P E_{\mathrm{dl}}$ describes the electric double-layer capacitance, in parallel with charge transfer resistance $R_{\mathrm{ct}}$. The fitted parameters of the Nyquist plots are listed in Table 3. The data in Table 3 illustrates that adding UHCI and $\mathrm{ZnSO}_{4}$, the inhibitive efficiency for carbon steel are $75.35 \%$ and $9.81 \%$, respectively, on condition that the total concentration is $100 \mathrm{mg} \cdot \mathrm{L}^{-1}$. Comparing the two data, it can be found that UHCI has certain corrosion inhibition for carbon steel in simulated RO product water, but only to add $\mathrm{ZnSO}_{4}$, the corrosion inhibition is not obviously. The inhibitive efficiency is improved visibly after adding the UHCI and $\mathrm{ZnSO}_{4}$ simultaneously, and as the proportion of UHCI increased, the value of the inhibitive efficiency firstly increased, continuously come up to a peak value $(96.28 \%)$, when the concentration of UHCI is $50 \mathrm{mg} \cdot \mathrm{L}^{-1}$, then let up while the concentration is increased. It tells that the best ratio of $\mathrm{UHCI}$ and $\mathrm{ZnSO}_{4}$ is $50: 50$, which shows a good consistency with Figure 3.

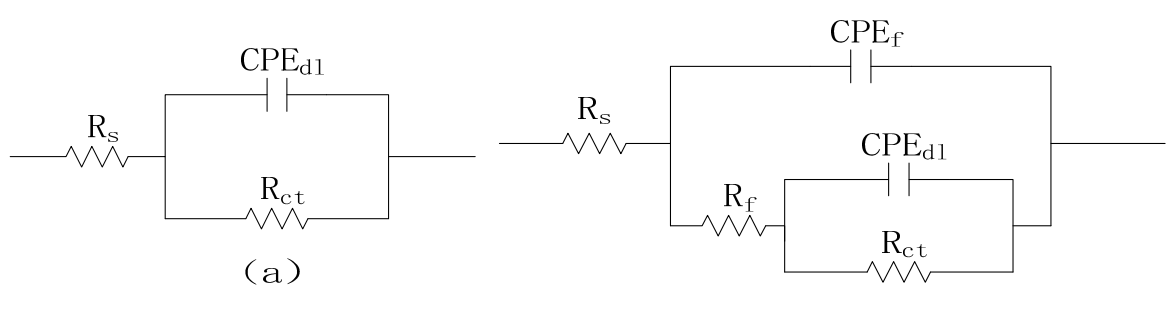

(b)

Figure 4. Equivalent circuit models of EIS.

\subsection{Surface analysis}

Figure 5 demonstrates the AFM images of carbon steel specimen immersed in simulated RO product water for one day without additives and with the mass concentration ratio of $\mathrm{UHCI}: \mathrm{ZnSO}_{4}=50: 50$, respectively. As shown in Figure 5(a), after immersion in the blank solution for one day, severe corrosion occurred on the surface of the electrode, and the surface was rough, while, in the solution with composite inhibitor, the surface of the electrode was smooth and almost no corrosion phenomenon happened. This is due to the composite inhibitor prevented the mass of the charge transfer, slowing down the corrosion of carbon steel effectively. 


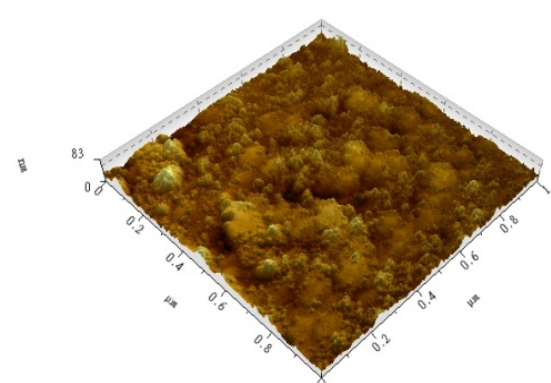

(a)

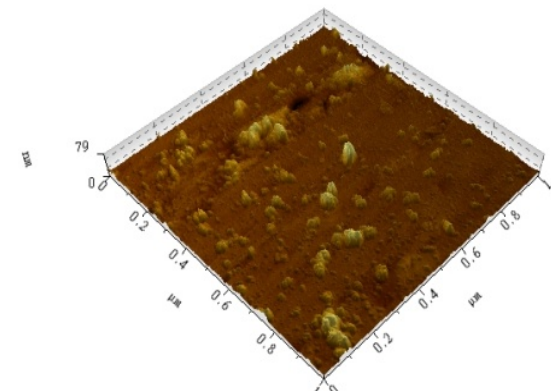

(b)

Figure 5. AFM images of the carbon steel specimens immersed in simulated RO product water for 1 day with different additives: $(a)$ blank, $(b) \mathrm{UHCI}: \mathrm{ZnSO}_{4}=50: 50$.

\subsection{XRD analysis}

Figure 6 presents XRD spectra of carbon steel specimen after immersion in simulated RO product water with $100 \mathrm{mg} \cdot \mathrm{L}^{-1} \mathrm{ZnSO}_{4}$ for one day. It clearly shows that the surface of the metal contains $\mathrm{ZnCl}_{2}$ and $\mathrm{Zn}(\mathrm{OH})_{2}$, from which it can be inferred that the corrosion inhibition of $\mathrm{ZnSO}_{4}$ for carbon steel is owing to the formation of $\mathrm{Zn}(\mathrm{OH})_{2}$ on the surface.

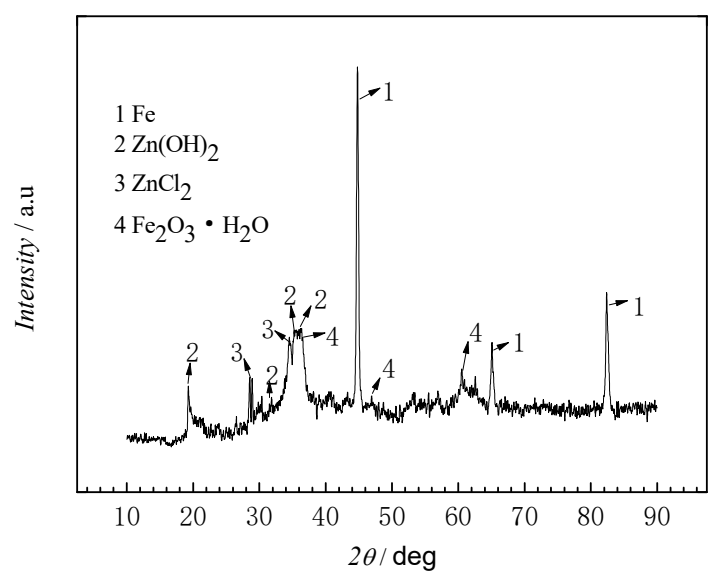

Figure 6. XRD spectra of carbon steel specimens immersed in simulated RO product water for 1 day with $100 \mathrm{mg} \cdot \mathrm{L}^{-1} \mathrm{ZnSO}_{4}$.

\section{Conclusions}

When the total concentration is $100 \mathrm{mg} \cdot \mathrm{L}^{-1}$ and the ratio of $\mathrm{UHCI}$ and $\mathrm{ZnSO}_{4}$ is $50: 50$, the corrosion inhibition for carbon steel immersed in simulated RO product water is best. The conclusions made from polarization curve measurements and EIS studies have good consistency.

The composite inhibitor is a mixed corrosion inhibitor. UHCI inhibits anode reaction and adsorbs on the metallic surface, preventing corrosion medium diffusion to the metallic surface while $\mathrm{ZnSO}_{4}$ inhibits the reaction of cathode in the form of $\mathrm{Zn}(\mathrm{OH})_{2}$ deposits on the metallic surface. 


\section{Acknowledgements}

The work was supported by Innovation Program of Shanghai Municipal Science and Technology Commission (14DZ2261000), China.

\section{References}

1. L. Zhang, L. Xie, H.L. Chen and C.J. Gao, Desalination, 2005, 182, 13.

2. Y.N. Man, X.J. Wang, Y.T. Wang and Y.J. Fang, Ind. Water Treat., 2014, 11, 8.

3. L.F. Greenlee, D.F. Lawler, B.D. Freeman, B. Marrot and P. Moulin, Water Res., 2009, 43, 2317.

4. A.U. Malik, I. Andijani, M. Mobin, S. Al-Fozan, F. Al-Muaili and M. Al-Hajiri, Desalin. Water Treat, 2010, 20, 22.

5. V.S. Marangou and K. Savvides, Desalination, 2001, 138, 251.

6. J. Li, G.C. Liu, W. Wang, Q. Zhang and G.H. Yi, Guangzhou Chem. Ind., 2009, 37, 95.

7. M. Zhang, H.H. Ge, X.J. Wang, X.J. Meng, Y.Z. Zhao and Q.Q. Liao, Anti-Corros. Meth. Mater., 2015, 62, 176.

8. J.Y. Hu, S.A. Cao and J.L. Xie, Acta Phys.-Chim. Sin., 2012, 28, 1153.

9. D.H. Zhou, S.H. Wu, L. Xiao, H.Y. Wang and J.Y. Hu, Corros. Prot., 2012, 33, 1057.

10. L. Yin, S.A. Cao, S.H. Wu and L. Xiao, Surf. Technol., 2012, 41, 43.

11. J.Y. Hu, S.A. Cao, L. Yin, Q.Q. Liang and J.L. Xie, Anti-Corros. Meth. Mater., 2012, 59, 305.

12. L. Birnhack, N. Voutchkov and O. Lahav, Desalination, 2011, 273, 6.

13. C.Z. Wei and S.R. Shen, Electr. Power Environ. Prot., 2010, 26, 48.

14. P.C. Okafor, X. Liu and Y.G. Zheng, Corros. Sci., 2009, 51, 761.

15. D.M. Ortega-Toledo, J.G. Gonzalez-Rodriguez, M. Casales, L. Martinez and A. Martinez-Villafane, Corros. Sci., 2011, 53, 3780.

16. Q.Q. Liao, Y.Q Chen, A.J Yan, W.T. Dong and H.H. Ge, Journal of Chinese Society for Corrosion and Protection, 2011, 31, 356.

17. Q.Q. Liang, S.A. Cao, L. Yin and L. Xiao, Journal of Chinese Society for Corrosion and Protection, 2012, 32, 412.

18. C.N. Cao, Principles of Electrochemistry of Corrosion, China Chemistry Press, Beijing, 2008. 